05,11

\title{
Магнитострикционные аномалии редкоземельных фаз Лавеса с морфотропным фазовым переходом
}

\author{
(C) Г.А. Политова ${ }^{1,2}$, М.А. Ганин ${ }^{1}$, А.Б. Михайлова ${ }^{1}$, А.В. Филимонов ${ }^{2,3}$ \\ ${ }^{1}$ Институт металлургии и материаловедения им. А.А. Байкова РАН, \\ Москва, Россия \\ ${ }^{2}$ Санкт-Петербургский политехнический университет Петра Великого, \\ Санкт-Петербург, Россия \\ ${ }^{3}$ Санкт-Петербургский Академический университет им. Ж.И. Алфёрова, \\ Санкт-Петербург, Россия \\ E-mail: gpolitova@gmail.com
}

Поступила в Редакцию 30 декабря 2019 г.

В окончательной редакции 30 декабря 2019 г.

Принята к публикации 10 января 2020 г.

\begin{abstract}
В последние годы в процессе поиска соединений с высокими или, наоборот, почти нулевыми значениями магнитострикции особое внимание привлек ряд псевдобинарных фаз Лавеса $R T_{2}$ с морфотропными фазовыми переходами, то есть системы соединений, имеющие на фазовой диаграмме морфотропную фазовую границу. В данной работе исследованы магнитные и магнитострикционные свойства многокомпонентных систем соединений $\mathrm{Tb}_{0.2} \mathrm{Dy}_{0.8-x} \mathrm{Gd}_{x} \mathrm{Co}_{2}$ и $\mathrm{Tb}_{0.2} \mathrm{Dy}_{0.8-x} \mathrm{Gd}_{x} \mathrm{Co}_{1.9} \mathrm{Al}_{0.1}$, в которых при замещении диспрозия гадолинием наблюдается морфотропный фазовый переход. Выявлена связь между температурным поведением, знаком и величиной магнитострикционных деформаций и типом искажения кубической решетки исследуемых фаз Лавеса. В области магнитных фазовых переходов исследован магнитокалорический эффект.
\end{abstract}

Ключевые слова: редкоземельные интерметаллиды, фазы Лавеса, магнитострикция, морфотропная фазовая граница, магнитокалорический эффект.

DOI: 10.21883/FTT.2020.06.49334.28M

\section{1. Введение}

Редкоземельные фазы Лавеса $R T_{2}(R-$ редкоземельный элемент; $T-3 d$-переходный металл) уже более полувека вызывают большой интерес специалистов в области как физики конденсированных сред, так и функциональных материалов, благодаря разнообразию наблюдаемых в них физических явлений, таких как гигантская магнитострикция, магнитокалорический и магнитоэлектрический эффекты [1-10]. Наиболее известной является система $\mathrm{TbFe}_{2}-\mathrm{DyFe}_{2}$, в которой при определенных условиях состава и температуры можно достичь компенсации магнитокристаллической анизотропии (МКА) и получить состав с гигантскими значениями магнитострикции $(\lambda s \sim 2000 \mathrm{ppm})$ в слабых магнитных полях в широкой области температур. В области комнатной температуры таким составом является $\mathrm{Tb}_{0.3} \mathrm{Dy}_{0.7} \mathrm{Fe}_{2}$, известный как Терфенол-D [2,6]. Данный материал широко используется в высокочувствительных датчиках, источниках ультразвука и других механизмах [11-13]. Работы по поиску материалов с компенсированной МКА и высокой магнитострикцией ведутся отечественными учеными давно [14-16], а в настоящее время вызывают большой интерес и в мировом сообществе $[17,18]$.

С начала открытия данного класса соединений считалось, что они имеют кубическую кристаллическую структуру типа $\mathrm{MgCu}_{2}$ (C15, пространственная группа $F d-3 m)$. Однако кубическая кристаллическая симметрия сохраняется в этих соединениях только в парамагнитном состоянии, когда спонтанная намагниченность $M_{S}$ и, следовательно, спонтанная деформация близка к нулю. При появлении спонтанной намагниченности в магнитоупорядоченном состоянии в кубическом ферромагнетике появляется и спонтанная деформация, которая понижает симметрию кристалла. При этом симметрия кристалла всегда зависит от направления $M_{S}[19,20]$. Например, если $M_{S}$ направлен вдоль оси $\langle 001\rangle$ кристалла, то создается тетрагональная симметрия с осью с кристалла, лежащей вдоль направления MS. Аналогично, когда MS направлен вдоль оси $\langle 111\rangle$, возникает ромбоэдрическое искажение решетки. Следовательно, в дополнение к упорядочению магнитного момента, при магнитном фазовом переходе происходит и изменение структуры. Однако, хотя изменение структуры при магнитном упорядочении происходит во всех псевдокубических ферромагнитных системах, искажение часто слишком мало, чтобы его обнаружить.

Благодаря современным синхротронным рентгеновским исследованиям удалось доказать, что разные магнитоупорядоченные состояния действительно соответствуют различным симметриям кристалла [21]. Фазовая же граница между магнитными ромбоэдрической и тетрагональной фазами (спин-переориентационный фазовый переход) является одновременно и границей кристаллографических фаз, то есть является магнитной морфотропной фазовой границей (МФГ). Системы составов с магнитной МФГ аналогичны давно обнаруженным и нашедшим практическое применение 
сегнетоэлектрикам с МФГ [22-24]. Магнитная МФГ формируется в зависимости от температуры на фазовой диаграмме. С помощью синхротронного рентгеновского излучения, в последние годы были обнаружены ферромагнитные системы с МФГ: $\mathrm{TbFe}_{2}-\mathrm{DyFe}_{2}$ и $\mathrm{TbCo}_{2}-\mathrm{DyCo}_{2} \quad[25,26], \quad \mathrm{TbCo}_{2}-\mathrm{GdCo}_{2} \quad[27]$, $\mathrm{TbFe}_{2}-\mathrm{GdFe}_{2} \quad[28], \quad \mathrm{TbCo}_{2}-\mathrm{NdCO}_{2} \quad[29] \quad$ и $\mathrm{DyCo}_{2}-\mathrm{DyFe}^{2}$ [30]. В отличие от сегнетоэлектрической МФГ, при которой всегда наблюдается усиление эффекта, ферромагнитные МФГ могут как усилить, так и ослабить магнитострикцию в зависимости от типа магнитного упорядочения исходных соединений на фазовой диаграмме. Усиление магнитострикционного эффекта было обнаружено в системах $\mathrm{TbFe}_{2}-\mathrm{DyFe}_{2}$ и $\mathrm{TbCo}_{2}-\mathrm{DyCo}_{2}$, тогда как МФГ в $\mathrm{TbCo}_{2}-\mathrm{GdCo}_{2}$ ослабляет магнитострикцию. Согласно [27] такие МФГ можно классифицировать как МФГ первого и второго типа, соответственно. Таким образом, определенный подбор исходных составов (с необходимым типом кристаллической и магнитной структуры) системы с МФГ, может позволить „настроить“ магнитострикционные свойства материала для различных инженерных приложений.

Целью данной работы было исследование влияния частичного замещения в редкоземельной подрешетке (диспрозия на гадолиний) и подрешетке $3 d$ металла (кобальта на алюминий) на магнитные и магнитострикционные свойства соединения $\mathrm{Tb}_{0.2} \mathrm{Dy}_{0.8} \mathrm{Co}_{2}$, выявление МФГ в данной системе. Соединение $\mathrm{Tb}_{0.2} \mathrm{Dy}_{0.8} \mathrm{Co}_{2}$ было взято в качестве исходного, поскольку является тройной точкой на фазовой диаграмме $\mathrm{TbCo}_{2}-\mathrm{DyCo}_{2}[25]$.

\section{2. Синтез соединений и методики эксперимента}

Синтез соединений проводился в дуговой электропечи фирмы Leybold-Heraeus прямым сплавлением в атмосфере аргона при избыточном давлении в камеpe равном $1.1 \mathrm{~atm}$. В качестве исходных компонентов использовались металлы с пониженным содержанием металлических и газообразующих примесей (чистота 99.978 mass.\%). В результате были получены поликристаллы массами по $20 \mathrm{~g}$ исходного состава $\mathrm{Tb}_{0.2} \mathrm{Dy}_{0.8} \mathrm{Co}_{2}$, сплавов с частичным замещением диспрозия на гадолиний $\mathrm{Tb}_{0.2} \mathrm{Dy}_{0.8-x} \mathrm{Gd}_{x} \mathrm{Co}_{2}(x=0.1,0.2$, $0.3,0.4$ и 0.5$)$, а также этой же серии образцов, но с частичным замещением $(5 \%)$ кобальта на алюминий $\mathrm{Tb}_{0.2} \mathrm{Dy}_{0.8-x} \mathrm{Gd}_{x} \mathrm{Co}_{1.9} \mathrm{Al}_{0.1}$. Трехкратная переплавка и последующий отжиг при температуре $850-900^{\circ} \mathrm{C}$ позволили получить однородные и практически однофазные образцы.

Съемка дифракционных спектров проводилась в $\mathrm{Cu} K_{\alpha}$-излучении при комнатной температуре на порошковых образцах при помощи рентгеновского дифрактометра „Ultima IV““ (Rigaku, Япония). Рентгеноструктурный и фазовый анализ полученных образцов был выполнен с использованием программного комплекса PDXL, интегрированном с международной базой данных
ICDD, а также в программном комплексе MAUD по методу Ритвельда.

Намагниченность образцов измерялась с помощью индукционного магнетометра (вставка к установке $\mathrm{MagEq}$ MMS 901, ООО „ПМТиК“, г. Троицк (Москва)). Данная установка позволяет получать петли гистерезиса в магнитных полях до $1.8 \mathrm{~T}$ в температурном интервале от 80 до $350 \mathrm{~K}$ как в автоматическом, так и в ручном режимах. Используя уравнения Максвелла и полученные изотермы намагниченности, были рассчитаны температурные зависимости изменения магнитной части энтропии. Магнитокалорический эффект измерялся также прямым методом (адиабатическое изменение температуры) с использованием установки MagEq MMS 901 (ООО „ПМТик“, г. Троицк (Москва)). Магнитострикция изучалась тензометрическим методом в том же диапазоне температур $80-350 \mathrm{~K}$ в магнитных полях до $1.2 \mathrm{~T}$. Измерения деформации проводились вдоль направления магнитного поля (продольная магнитострикция, $\lambda_{\|}$) и перпендикулярно ему (поперечная магнитострикция, $\lambda_{\perp}$ ).

\section{3. Результаты и обсуждение}

В результате проведенных рентгеноструктурных и фазовых исследований при комнатной температуре установлено, что все соединения, как исходное, так и замещенные, имеют кубическую структуру фазы Лавеса $\left(\mathrm{MgCu}_{2}\right) C 15$ (пр.гр.: $\left.F d-3 m\right)$. Дифракционные спектры составов с алюминием представлены на рис. $1, a$. Расщеплений пиков, свидетельствующих о искажении кубической структуры выявить не удалось как в области комнатной температуры, так и при низкотемпературных исследованиях, проводимых нами ранее [31,32]. Все исследуемые составы оказались практически однофазными, количество второй фазы типа $R \mathrm{Co}_{3}$ для разных стехиометрических композиций не превышает $3-5 \%$, а в некоторых случаях данная фаза практически полностью отсутствует. Методом Ритвельда определенны параметры элементарной ячейки основной фазы $\mathrm{RCo}_{2}$ исследованных сплавов (таблица).

Как видно из таблицы и из рис. $1, b$, с увеличением содержание гадолиния в системах $\mathrm{Tb}_{0.2} \mathrm{Dy}_{0.8-x} \mathrm{Gd}_{x} \mathrm{Co}_{2}$ и $\mathrm{Tb}_{0.2} \mathrm{Dy}_{0.8-x} \mathrm{Gd}_{x} \mathrm{Co}_{1.9} \mathrm{Al}_{0.1}$ наблюдается практически линейный рост параметра и объема элементарной ячейки. Объем элементарной ячейки при замещении $10 \%$ диспрозия на гадолиний увеличивается в среднем на $0.3 \%$, в то время как при замещении $5 \%$ кобальта на алюминий - в среднем на $0.7 \%$.

На рис. 2, a показана температурная зависимость намагниченности $M(T)$ соединений $\mathrm{Tb}_{0.2} \mathrm{Dy}_{0.8-x} \mathrm{Gd}_{x} \mathrm{Co}_{2}$ в магнитном поле $0.01 \mathrm{~T}$. Аналогичный вид кривых и в системе с алюминием. На вставке к рис. 2, $a$ приведена петля гистерезиса для исходного состава, измеренная при температуре $100 \mathrm{~K}$. Видно, что в поле $1.8 \mathrm{~T}$ намагниченность почти выходит на насыщение, величина коэрцитивной силы составляет $50 \mathrm{Oe}$. В замещенных составах, а также с ростом температуры, коэрцитивная 
Основные структурные и магнитные характеристики соединений $\mathrm{Tb}_{0.2} \mathrm{Dy}_{0.8-x} \mathrm{Gd}_{x} \mathrm{Co}_{2}$ и $\mathrm{Tb}_{0.2} \mathrm{Dy}_{0.8-x} \mathrm{Gd}_{x} \mathrm{Co}_{1.9} \mathrm{Al}_{0.1}(x=0.1,0.2,0.3$, 0.4 и 0.5$)$.

\begin{tabular}{|c|c|c|c|c|c|c|c|}
\hline Соединение & $a, \AA$ & $T_{\mathrm{C}}, \mathrm{K}$ & $T_{S R}, \mathrm{~K}^{*}$ & $\lambda_{a}^{\max } \mathrm{ppm}^{*}$ & $\lambda_{\omega}^{\max }, \mathrm{ppm}^{*}$ & $-\Delta S_{M}^{\max }, \mathrm{J} / \mathrm{kg} \mathrm{K}^{* *}$ & $\Delta T_{a d}^{\max }, \mathrm{K}^{* *}$ \\
\hline $\mathrm{Tb}_{0.2} \mathrm{Dy}_{0.8} \mathrm{Co}_{2}$ & 7.191 & 161 & - & - & 720 & 3.4 & 4.1 \\
\hline $\mathrm{Tb}_{0.2} \mathrm{Dy}_{0.7} \mathrm{Gd}_{0.1} \mathrm{Co}_{2}$ & 7.201 & 190 & 150 & 180 & 430 & 2.9 & 1.85 \\
\hline $\mathrm{Tb}_{0.2} \mathrm{Dy}_{0.6} \mathrm{Gd}_{0.2} \mathrm{Co}_{2}$ & 7.206 & 218 & 157 & 125 & 260 & 1.9 & 1.35 \\
\hline $\mathrm{Tb}_{0.2} \mathrm{Dy}_{0.5} \mathrm{Gd}_{0.3} \mathrm{Co}_{2}$ & 7.212 & 245 & 155 & 170 & 240 & 1.5 & 1.2 \\
\hline $\mathrm{Tb}_{0.2} \mathrm{Dy}_{0.4} \mathrm{Gd}_{0.4} \mathrm{Co}_{2}$ & 7.216 & 276 & 139 & 80 & 250 & 1.6 & 1.2 \\
\hline $\mathrm{Tb}_{0.2} \mathrm{Dy}_{0.3} \mathrm{Gd}_{0.5} \mathrm{Co}_{2}$ & 7.219 & 296 & 110 & 50 & 240 & 1.4 & 1.2 \\
\hline $\mathrm{Tb}_{0.2} \mathrm{Dy}_{0.7} \mathrm{Gd}_{0.1} \mathrm{Co}_{1.9} \mathrm{Al}_{0.1}$ & 7.215 & 220 & 156 & 310 & 315 & 1.9 & 1.4 \\
\hline $\mathrm{Tb}_{0.2} \mathrm{Dy}_{0.6} \mathrm{Gd}_{0.2} \mathrm{Co}_{1.9} \mathrm{Al}_{0.1}$ & 7.222 & 242 & 154 & 240 & 195 & 1.6 & 1.15 \\
\hline $\mathrm{Tb}_{0.2} \mathrm{Dy}_{0.5} \mathrm{Gd}_{0.3} \mathrm{Co}_{1.9} \mathrm{Al}_{0.1}$ & 7.230 & 272 & 153 & 265 & 195 & 1.2 & 1.0 \\
\hline $\mathrm{Tb}_{0.2} \mathrm{Dy}_{0.4} \mathrm{Gd}_{0.4} \mathrm{Co}_{1.9} \mathrm{Al}_{0.1}$ & 7.235 & 286 & 139 & 285 & 160 & 1.2 & 1.0 \\
\hline $\mathrm{Tb}_{0.2} \mathrm{Dy}_{0.3} \mathrm{Gd}_{0.5} \mathrm{Co}_{1.9} \mathrm{Al}_{0.1}$ & 7.241 & 317 & 111 & 306 & 175 & 1.1 & 1.0 \\
\hline
\end{tabular}

Примечание. * в магнитном поле $1.2 \mathrm{~T} ;{ }^{* *}$ в магнитном поле $1.8 \mathrm{~T}$.

сила уменьшается до 5 Ое, что отлично характеризует данные материалы как магнитомягкие.

По пику на температурной зависимости $d M / d T$ определена температура Кюри $\left(T_{\mathrm{C}}\right)$ для всех соединений. Для уточнения полученных значений температур был
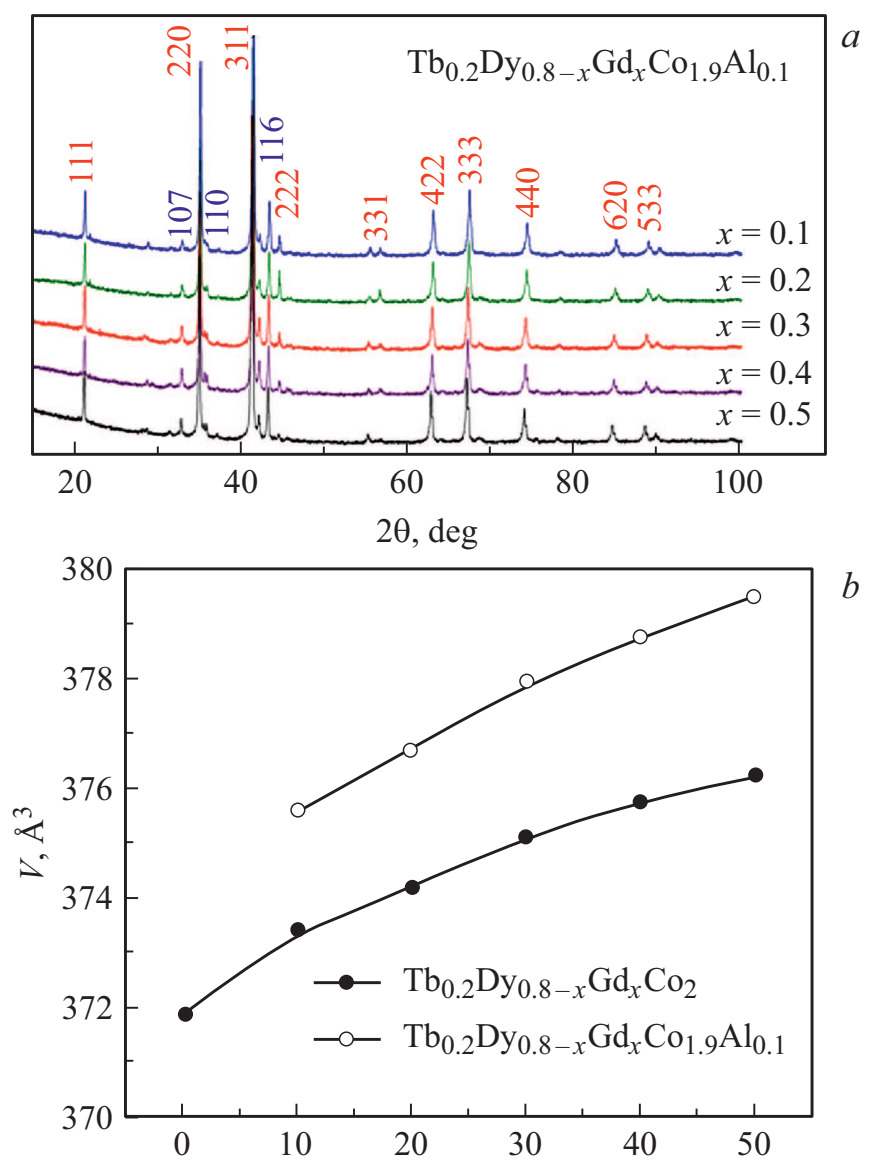

$\mathrm{Tb}_{0.2} \mathrm{Dy}_{0.8} \mathrm{Co}_{2} \quad \mathrm{~mol} \%$ Dy replacing $\mathrm{Gd}$

Рис. 1. Дифракционные спектры $(a)$ и $(b)$ концентрационная зависимость объема элементарной ячейки соединений $\mathrm{Tb}_{0.2} \mathrm{Dy}_{0.8-x} \mathrm{Gd}_{x} \mathrm{Co}_{2}$ и $\mathrm{Tb}_{0.2} \mathrm{Dy}_{0.8-x} \mathrm{Gd}_{x} \mathrm{Co}_{1.9} \mathrm{Al}_{0.1}$. применен метод Белова-Аррота, позволяющий определить температуру Кюри по изотермам намагниченности, измеренным в области перехода. Полученные значения приведены в таблице. Как в системе с алюминием, так и без него, замещение диспрозия на гадолиний приводит к линейному росту температуры Кюри. Скорости роста составляют 24 и $27 \mathrm{~K} / 10 \%$. Частичное же замещение кобальта на алюминий (5\%) приводит к увеличению температуры Кюри в среднем на $22 \mathrm{~K}$.

При анализе магнитных фазовых диаграмм систем $\mathrm{TbCo}_{2}-\mathrm{DyCo}_{2} \quad[25]$ и $\mathrm{TbCo}_{2}-\mathrm{GdCo}_{2}$ [27], можно предположить наличие МФГ в системе $\mathrm{Tb}_{0.2} \mathrm{Dy}_{0.8} \mathrm{Co}_{2}-\mathrm{Tb}_{0.2} \mathrm{Gd}_{0.8} \mathrm{Co}_{2}$. Однако, в слабых магнитных полях особенностей на температурной зависимости намагниченности, связанных со спин-переориентационными фазовыми переходами выявлено не было. C ростом же напряженности внешнего магнитного поля данные особенности начинают проявляться, что хорошо видно на рис. $2, b$. Однако определение точной температуры спиновой переориентации из полученных данных затруднительно.

Известно [9,33], что фазы Лавеса $R_{\mathrm{Co}_{2}}$, наряду с высокими магнитострикционными свойствами, в области температуры Кюри демонстрируют значительный по величине магнитокалорический эффект. Из изотерм намагниченности, косвенным метом, используя уравнения Максвелла [33], была определена величина МКЭ исследованных соединений (см. таблицу). Температурная зависимость изменения магнитной части энтропии $\left(-\Delta S_{M}\right)$ для системы $\mathrm{Tb}_{0.2} \mathrm{Dy}_{0.8-x} \mathrm{Gd}_{x} \mathrm{Co}_{2}$ при изменении величины магнитного поля $1.8 \mathrm{~T}$ показана на рис. 3, $a$. Видно, что в области температуры Кюри наблюдается максимум $-\Delta S_{M}$. Определенные значения $-\Delta S_{M}$ хорошо коррелируют с полученными нами ранее [31] значениями адиабатического изменения температуры образцов, представленными в таблице. В интервале температур $100-200 \mathrm{~K}$ на зависимостях $\Delta S_{M}(T)$ также наблюдаются аномалии, связанные с изменением магнитной структуры соединений. 

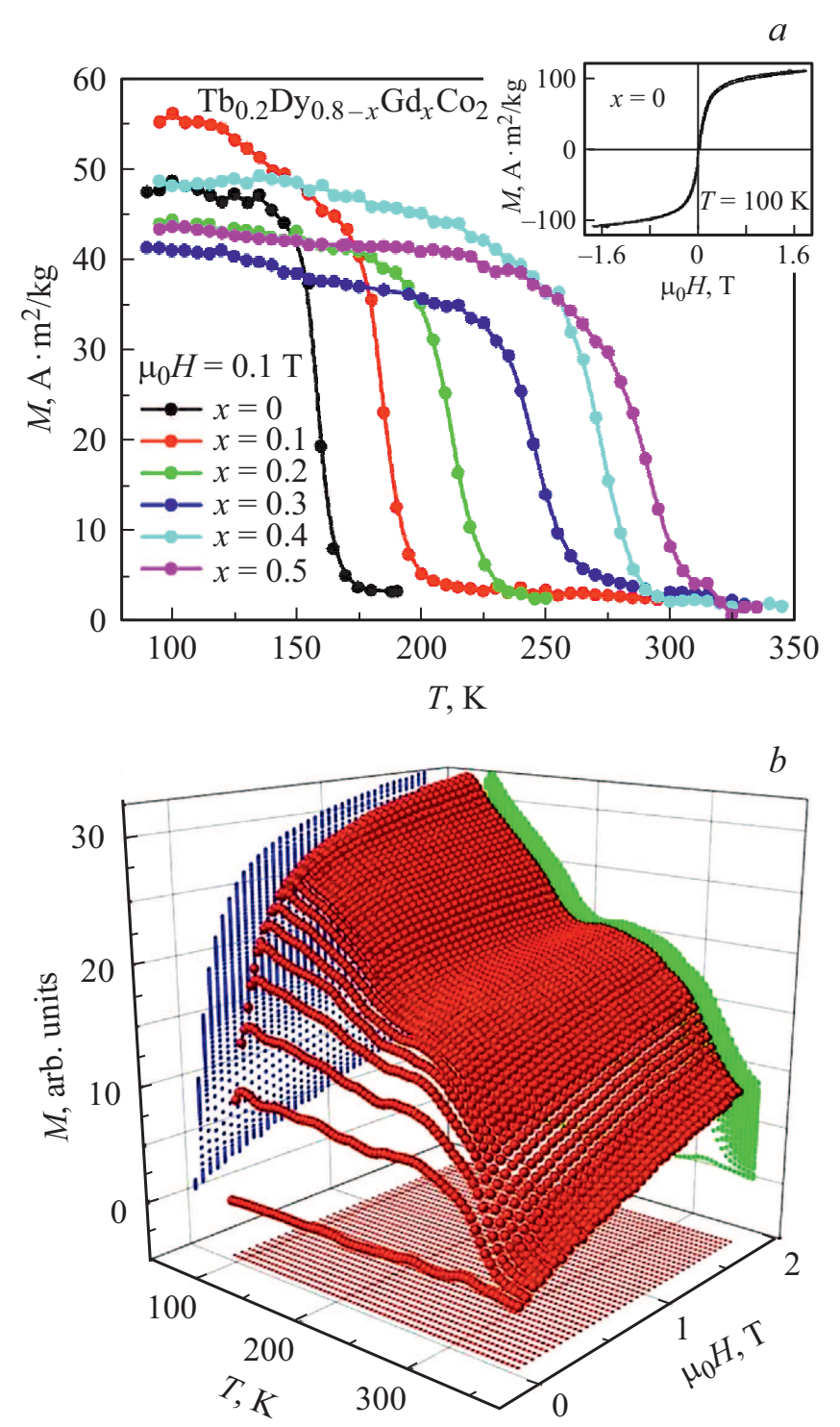

Рис. 2. Температурные зависимости намагниченности соединений $\mathrm{Tb}_{0.2} \mathrm{Dy}_{0.8-x} \mathrm{Gd}_{x} \mathrm{Co}_{2}(a)$ и $3 \mathrm{D}$ зависимость намагниченности от температуры и величины магнитного поля для $\mathrm{Tb}_{0.2} \mathrm{Dy}_{0.3} \mathrm{Gd}_{0.5} \mathrm{Co}_{1.9} \mathrm{Al}_{0.1}(b)$. Вставка к рис. 2, $a$ : Петля гистерезиса дляTb ${ }_{0.2} \mathrm{Dy}_{0.8} \mathrm{Co}_{2}$ при $T=100 \mathrm{~K}$.

Для этих же образцов были проведены исследования магнитострикционных свойств. Измерения проводились на поликристаллических образцах. Из полученных значений продольной и поперечной магнитострикции были рассчитаны объемная $\lambda_{\omega}$ и анизотропная $\lambda_{a}$ магнитострикция по следующим выражениям: $\lambda_{\omega}=\lambda_{\|}+2 \lambda_{\perp}$, $\lambda_{a}=\lambda_{\|}-\lambda_{\perp}$. Максимальные значения объемной и анизотропной магнитострикции представлены в таблице. Известно [3], что в области температуры Кюри объемная магнитострикция и МКЭ должны быть пропорциональны квадрату намагниченности и, следовательно, между ними должна наблюдаться прямая зависимость [37]. Как видно из рис. $3, b$, объемная магнитострикция, так же как и величина МКЭ соединений $\mathrm{Tb}_{0.2} \mathrm{Dy}_{0.8-x} \mathrm{Gd}_{x} \mathrm{Co}_{2}$ уменьшается с увеличением содержания гадолиния, а при $x=0.3-0.5$ имеет постоянную величину.

Для исходного соединения $\mathrm{Tb}_{0.2} \mathrm{Dy}_{0.8} \mathrm{Co}_{2}$ при температуре жидкого азота продольная магнитострикция отрицательна, а поперечная магнитострикция положительна. Это означает, что кубическая решетка сжимается, аналогично поведению $\mathrm{SmFe}_{2}$ [39]. С ростом температуры абсолютные значения магнитострикции монотонно уменьшаются. Вблизи температуры Кюри продольная и поперечная магнитострикции имеют положительный знак. Максимальное значение магнитострикции соответствует температуре Кюри и не зависит от величины приложенного магнитного поля [36].

Для всех исследованных замещенных соединений ниже температуры Кюри температурные зависимости продольной и поперечной магнитострикции немонотонны и имеют экстремумы. На рис. 4, $a$ в качестве примера приведены температурные и полевые зависимости продольной магнитострикции соединения
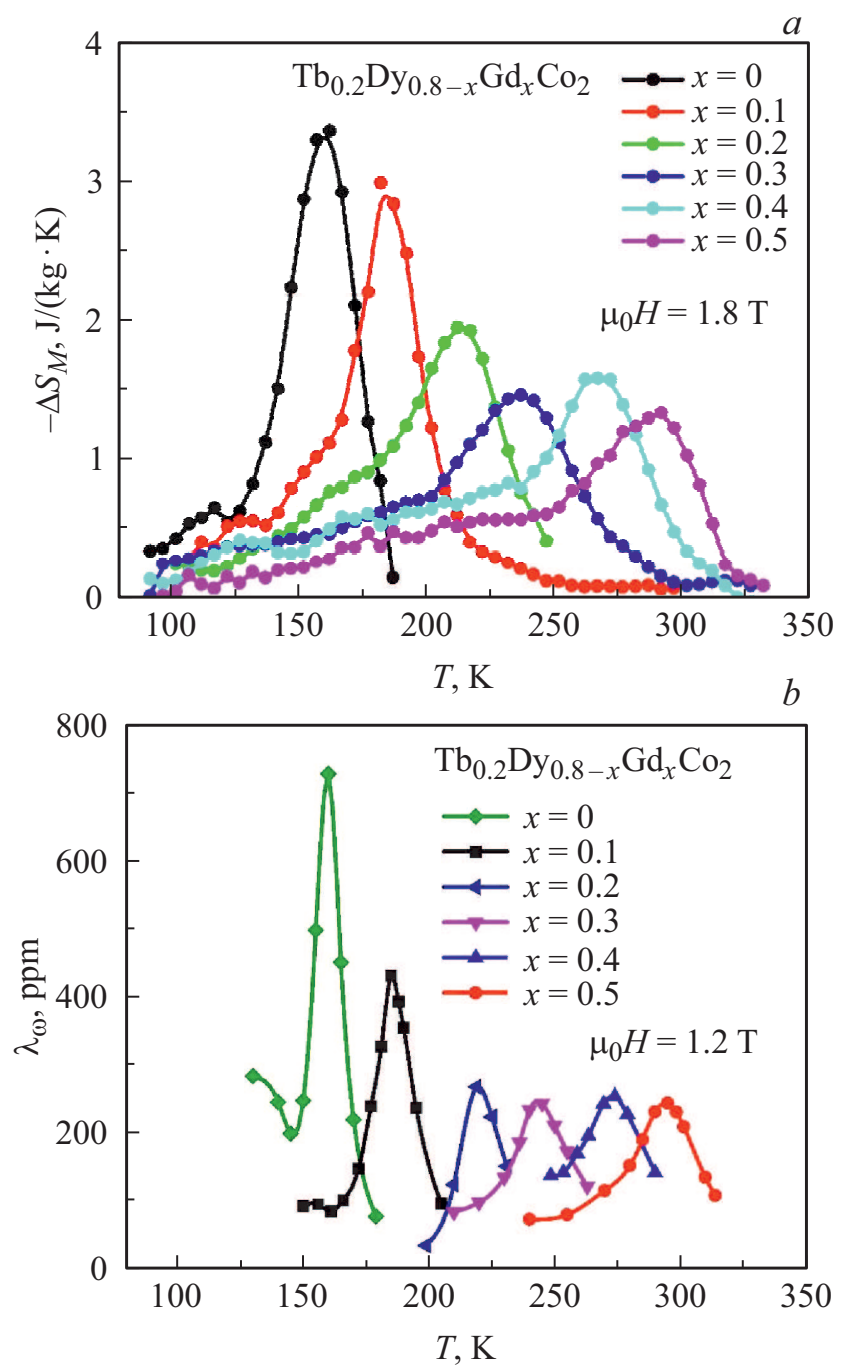

Рис. 3. Температурные зависимости изменения магнитной части энтропии $(a)$ и объемной магнитострикции $(b)$ соединений $\mathrm{Tb}_{0.2} \mathrm{Dy}_{0.8-x} \mathrm{Gd}_{x} \mathrm{Co}_{2}$. 

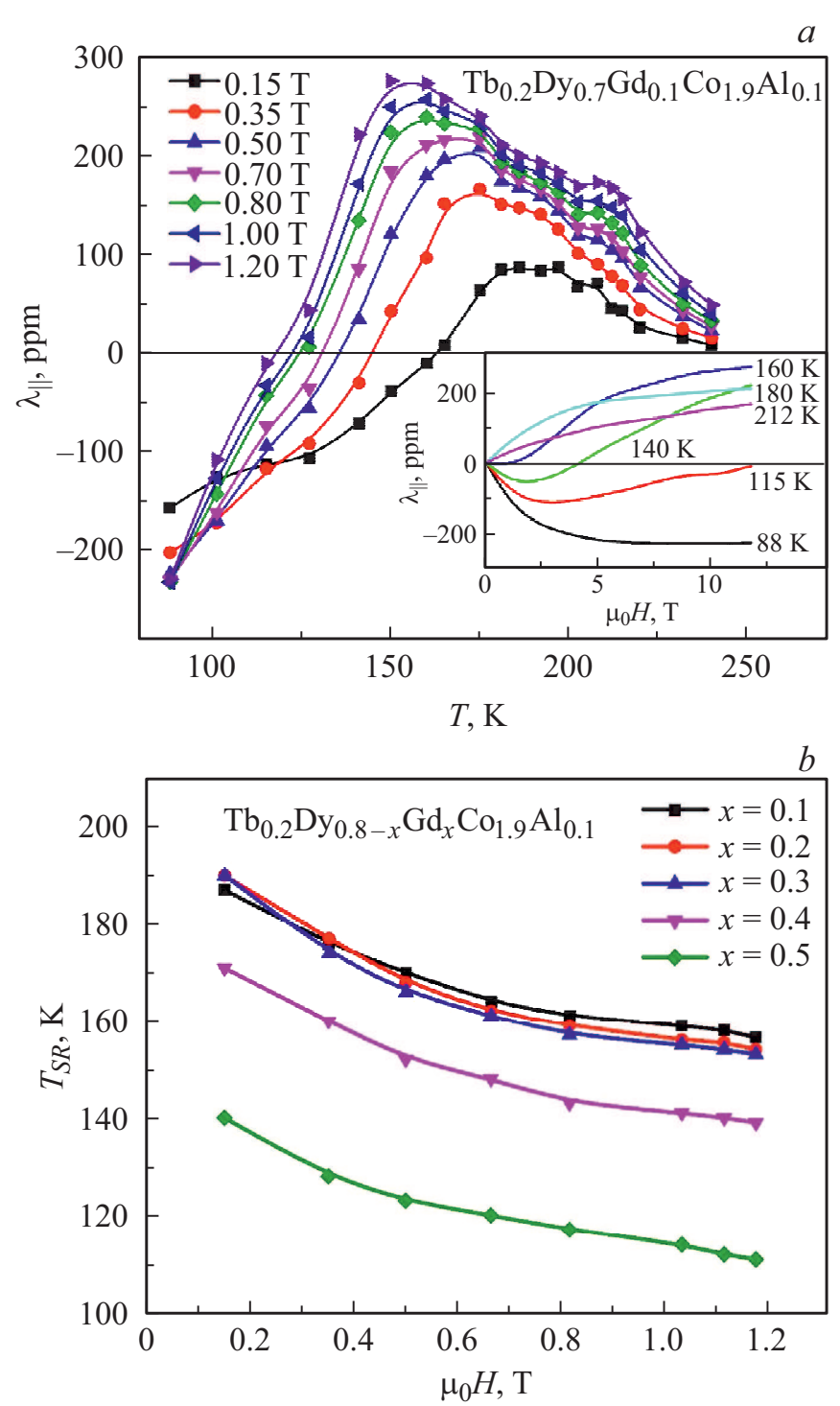

Рис. 4. (a) Температурные зависимости продольной магнитострикции соединения $\mathrm{Tb}_{0.2} \mathrm{Dy}_{0.7} \mathrm{Gd}_{0.1} \mathrm{Co}_{1.9} \mathrm{Al}_{0.1} ;(b)$ зависимости температуры спин-переориентационного перехода от величины магнитного поля. На вставке к рис. 4, $а$ : полевые зависимости продольной магнитострикции.

$\mathrm{Tb}_{0.2} \mathrm{Dy}_{0.7} \mathrm{Gd}_{0.1} \mathrm{Co}_{1.9} \mathrm{Al}_{0.1}$. При максимальном приложенном внешнем магнитном поле $(1.2 \mathrm{~T})$ хорошо видны два максимума в области магнитных фазовых переходов. При малых полях для данного состава максимумы сливаются в один, что связано с близкими значениями температур переходов. Правый максимум соответствует температуре Кюри, то есть переходу из магнитоупорядоченного в магниторазупорядоченное состояние. Как видно, температура этого перехода, также как у исходного состава $\mathrm{Tb}_{0.2} \mathrm{Dy}_{0.8} \mathrm{Co}_{2}$, не зависит от величины приложенного поля. Ниже температуры Кюри наблюдается увеличение магнитострикции, что свидетельствует о другом типе искажения кубической решетки, чем в соединении $\mathrm{Tb}_{0.2} \mathrm{Dy}_{0.8} \mathrm{Co}_{2}$. В этом случае кубическая решетка растягивается, что аналогично растяжению вдоль направления „111“ кубической решетки соединения $\mathrm{TbFe}_{2}$ в магнитоупорядоченном состоянии. Левый максимум на рисунке (при более низких температурах) соответствует температуре спин-переориентационного фазового перехода из ромбоэдрической фазы в тетрагональную, или, как было отмечено выше МФГ. Температура данного перехода сильно зависит от величины приложенного магнитного поля. Так, при изменении магнитного поля от 0.15 до $1.2 \mathrm{~T}$ температура перехода уменьшается на $30 \mathrm{~K}$. Данная зависимость носит немонотонный характер, присуща всем составам системы и представлена на рис. $4, b$.

Наряду с магнитострикцией насыщения, наиболее важной характеристикой магнитострикционных матери-
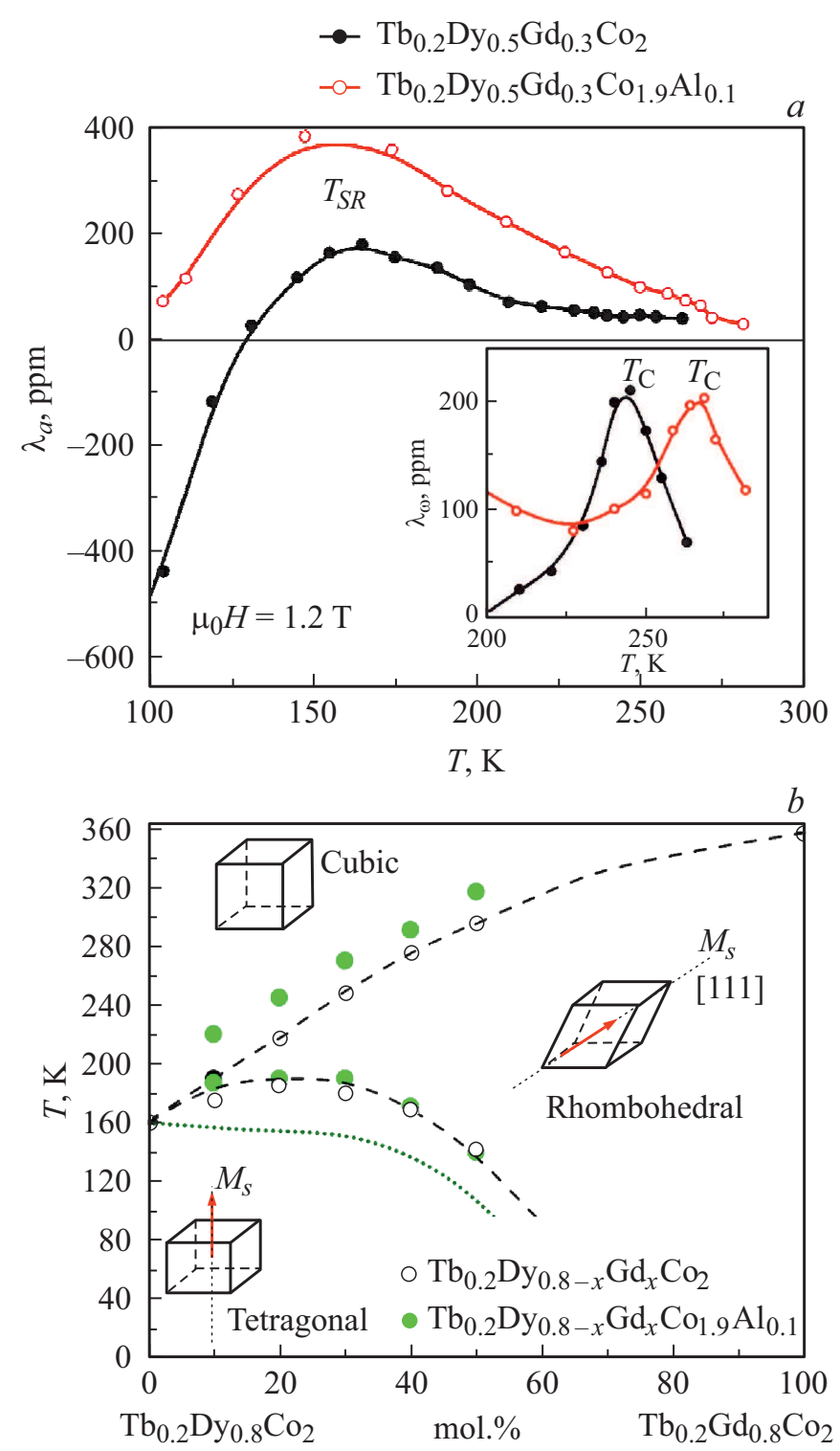

Рис. 5. (a) Температурные зависимости анизотропной и объемной (вставка) магнитострикции соединений $\mathrm{Tb}_{0.2} \mathrm{Dy}_{0.5} \mathrm{Gd}_{0.3} \mathrm{Co}_{2}$ и $\mathrm{Tb}_{0.2} \mathrm{Dy}_{0.5} \mathrm{Gd}_{0.3} \mathrm{Co}_{1.9} \mathrm{Al}_{0.1} ;$ (b) Магнитоструктурная фазовая диаграмма систем $\mathrm{Tb}_{0.2} \mathrm{Dy}_{0.8-x} \mathrm{Gd}_{x} \mathrm{Co}_{2}$ и $\mathrm{Tb}_{0.2} \mathrm{Dy}_{0.8-x} \mathrm{Cd}_{x} \mathrm{Co}_{1.9} \mathrm{Al}_{0.1}$. 
алов при их практическом применении является магнитострикционная восприимчивость $d \lambda / d H$, поскольку она отражает способность генерировать большую магнитострикцию небольшим магнитным полем. На вставке к рис. 4, a показаны полевые зависимости магнитострикции этого соединения при различных температурах. Видно, что в области МФГ магнитострикция достигает наибольших значений и уже в магнитном поле $1.2 \mathrm{~T}$ стремится к насыщению. Однако, поскольку температура МФГ сильно зависит от величины магнитного поля, возможно получение изотерм магнитострикции либо с высокими значениями магнитострикции в высоких полях, но „провалом“ при низких , то есть низкой $d \lambda / d H$ (изотерма при $160 \mathrm{~K}$ ), либо высокой $d \lambda / d H$, но меньшими значениями магнитострикции насыщения (изотерма при $180 \mathrm{~K}$ ). Стоит отметить и наблюдаемое изменение знака продольной магнитострикции с увеличением напряженности магнитного поля. Материалы с подобным эффектом могут найти практическое применение [30].

При анализе температурных зависимостей магнитострикции соединений $\mathrm{Tb}_{0.2} \mathrm{Dy}_{0.8-x} \mathrm{Gd}_{x} \mathrm{Co}_{2}$ и $\mathrm{Tb}_{0.2} \mathrm{Dy}_{0.8-x} \mathrm{Gd}_{x} \mathrm{Co}_{1.9} \mathrm{Al}_{0.1}$ установлено, что при частичном замещении кобальта алюминием (5\%) температура Кюри исследованных соединений увеличивается в среднем на $20 \mathrm{~K}$, в то время как температура спиновой переориентации практически не меняется (рис. 5, a).

В результате проведенных исследований магнитных и магнитострикционных свойств систем $\mathrm{Tb}_{0.2} \mathrm{Dy}_{0.8-x} \mathrm{Gd}_{x} \mathrm{Co}_{2} \quad$ и $\mathrm{Tb}_{0.2} \mathrm{Dy}_{0.8-x} \mathrm{Gd}_{x} \mathrm{Co}_{1.9} \mathrm{Al}_{0.1}$. нами была построена магнито-структурная фазовая диаграмма (рис. 5,b). Исследованные нами соединения по виду данной диаграммы можно отнести к системе соединений с МФГ первого типа, которые являются перспективными для использования в устройствах, требующих высоких значений магнитострикции. Положение МФГ сильно зависит от напряженности внешнего магнитного поля, под действием которого смещается в область низких температур.

\section{4. Заключение}

Таким образом, в системе $\mathrm{Tb}_{0.2} \mathrm{Dy}_{0.8} \mathrm{Co}_{2}-\mathrm{Tb}_{0.2} \mathrm{Gd}_{0.8} \mathrm{Co}_{2} \quad$ и системе $\mathrm{c}$ частичным (5\%) замещением кобальта на алюминий $\mathrm{Tb}_{0.2} \mathrm{Dy}_{0.8} \mathrm{Co}_{1.9} \mathrm{Al}_{0.1}-\mathrm{Tb}_{0.2} \mathrm{Gd}_{0.8} \mathrm{Co}_{1.9} \mathrm{Al}_{0.1}$ была обнаружена магнитная морфотропная фазовая граница, в области которой происходит усиление магнитострикционных свойств. Кроме того, в ряде соединений наблюдается смена знака продольной магнитострикции в зависимости от температуры и напряженности внешнего магнитного поля. Установлено, что при частичном замещении кобальта алюминием (5\%) температура Кюри исследованных соединений увеличивается в среднем на $20 \mathrm{~K}$, в то время как температура спиновой переориентации практически не меняется. Температура Кюри не зависит от напряженности внешнего магнитного поля, в то время как МФГ сдвигается в область низких температур. В области температуры Кюри в системах $\mathrm{Tb}_{0.2} \mathrm{Dy}_{0.8-x} \mathrm{Gd}_{x} \mathrm{Co}_{2} \quad$ и $\mathrm{Tb}_{0.2} \mathrm{Dy}_{0.8-x} \mathrm{Gd}_{x} \mathrm{Co}_{1.9} \mathrm{Al}_{0.1}$ величина магнитокалорического эффекта пропорциональна объемной магнитострикции. При замещении диспрозия гадолинием МКЭ сначала уменьшается, а, начиная с $x=0.3$, имеет постоянное значение.

\section{Благодарности}

Авторы благодарят профессора, д.ф.-м.н. С.А. Никитина и к.ф.-м.н. Н.Ю. Панкратова (Московский Государственный Университет им. М.В. Ломоносова, физический факультет) за предоставление возможности проведения магнитострикционных исследований.

\section{Финансирование работы}

Работа выполнена при поддержке Российского фонда фундаментальных исследований, проект № 18-03-00798-a.

\section{Конфликт интересов}

Авторы заявляют, что у них нет конфликта интересов.

\section{Список литературы}

[1] K.H.J. Buschow. Rep. Prog. Phys. 40, 1179 (1977).

[2] A.E. Clark. Ferromagnetic Materials. North-Holland, Amsterdam, (1980).

[3] К.П. Белов Магнитострикционные явления и их технические приложения.Наука, М., (1987).

[4] С.А. Никитин. Магнитные свойства редкоземельных металлов и их сплавов. М., (1989).

[5] A.V. Andreev. Thermal expansion anomalies and spontaneous magnetostriction in rare-earth intermetallics with cobalt and iron. In: Handbook of Magnetic Materials / Ed. K.H.J. Buschow (1995). T. 8. C. 2.

[6] U. Atzmony, M.P. Dariel, G. Dublon. Phys. Rev. B 15, 3565 (1977).

[7] M.D. Kuz'min, A.M. Tishin. In: Handbook of Magnetic Materials Elsevier, Amsterdam, (2007), T. 17, P. 149.

[8] A. del Moral. Handbook of Magnetostriction and Magnetostrictive Materials Zaragoza, Spain (2008).

[9] N. Duc, D.K. Anh, P. Brommer. Phys. B: Condens. Matter 319, $1-4,1$ (2002).

[10] V.B. Chzhan, I.S. Tereshina, A.Yu. Karpenkov, E.A. TereshinaChitrova. Acta Mater. 154, 303 (2018).

[11] N.J. Wang, Y. Liu, H.W. Zhang, X. Chen, Y.X. Li. China Foundry 13, 2, 75 (2016).

[12] A.G. Olabi, A. Grunwald. Mater. Des. 29, 469 (2008).

[13] G. Lanza, G. Breglio, M. Giordano, A. Gaddi, S. Buontempo, A. Cusano. Sens. Actuators A 172, 420 (2011).

[14] И.С. Терешина, А.П. Туляков, С.А. Никитин, Г.А. Политова, К.П. Скоков. ФТТ 49, 2, 304 (2007).

[15] И.С. Терёшина, С.А. Никитин, Г.А. Политова, А.А. Опаленко, Е.А. Терёшина, И.В. Телегина. ФТТ 51, 1, 85 (2009).

[16] Г.А. Политова, И.С. Терешина, С.А. Никитин, Т.Г. Соченкова, В.Н. Вербецкий, А.А. Саламова, М.В. Макарова. ФТТ 47, 10, 1834 (2005). 
[17] W.J. Ren, Z.D. Zhang. Chin. Phys. B. 22, 7, 077507 (2013).

[18] G.B. Zhang, W.G. Zheng, Y. Cui, Y.G. Shi, D.N. Shi. J. Superconductivity Novel Magn. 31, 2217 (2018).

[19] E.R. Callen, H.B. Callen. Phys. Rev. 129, 578 (1963).

[20] S. Yang, H. Bao, Ch. Zhou, Yu. Wang, X. Ren, X. Song, M. Yoshitaka, K. Yoshio, T. Masahiko, K. Keisuke. Chin. Phys. B 22, 4 (2013).

[21] D.C. Jiles. Acta Mater. 51, 5907 (2003).

[22] M. Ahart, M. Somayazulu, R.E. Cohen, P. Ganesh, P. Dera, H.K. Mao, R.J. Hemley, Y. Ren, P. Liermann, Z. Wu. Nature (London) 451, 545 (2008).

[23] W.F. Liu, X.B. Ren. Phys. Rev. Lett. 103, 257602 (2009).

[24] R.G. Burkovsky, Yu. Bronwald, D. Andronikova, B. Wehinger, M. Krisch, J. Jacobs, D. Gambetti, K. Roleder, A. Majchrowski, A.V. Filimonov, A.I. Rudskoy, S.B. Vakhrushev, A.K. Tagantsev. Sci. Rep. 7, 41512 (2017).

[25] S. Yang, H.X. Bao, C. Zhou, Y. Wang, X.B. Ren, Y. Matsushita, Y. Katsuya, M. Tanaka, K. Kobayashi, X.P. Song, J.R. Gao. Phys. Rev. Lett. 104, 197201 (2010).

[26] R. Bergstrom, Jr., M. Wuttig, J. Cullen, P. Zavalij, R. Briber, C. Dennis, V.O. Garlea, M. Laver. Phys. Rev. Lett. 111, 017203 (2013).

[27] C. Zhou, S. Ren, H. Bao, S. Yang, Y.G. Yao, Y.C. Ji, X.B. Ren, Y. Matsushita, Y. Katsuya, M. Tanaka, K. Kobayashi. Phys. Rev. B 89, 100101(R) (2014).

[28] A. Murtaza, S. Yang, M. Mi, C. Zhou, J.Q. Wang, R. Zhang, X.Q. Liao, Y. Wang, X.B. Ren, X.P. Song, Y. Ren. Appl. Phys. Lett. 106, 132403 (2015).

[29] A. Murtaza, S. Yang, C. Zhou, T.Y. Chang, K.Y. Chen, F.H. Tian, X.P. Song, M.R. Suchomel, Y. Ren. Appl. Phys. Lett. 109, 052904 (2016).

[30] T.Y. Ma, X.L. Liu, J. Gou, Y. Wang, C. Wu, C. Zhou, Y. Wang, S. Yang, X.B. Ren. Phys. Rev. Mater. 3, 034411 (2019).

[31] G. Politova, T. Kaminskaya, A. Mikhailova, M. Ganin, O. Alekseeva, P. Vanina, B. Nacke, A. Filimonov, A. Rudskoy, G. Burkhanov. Key Eng. Mater. 806, 136 (2019)

[32] G.A. Politova, N.Yu. Pankratov, P.Yu. Vanina, A.V. Filimonov, A.I. Rudskoy, G.S. Burkhanov, A.S. Ilyushin, I.S. Tereshina. J. Magn. Magn. Mater. 470, 50-54 (2019).

[33] A.M. Tishin, Y.I. Spichkin. The Magnetocaloric Effect and its Applications. Institute of Physics. N.Y. (2003).

[34] I.S. Tereshina, J. Cwik, E.A. Tereshina, G. Politova, G. Burkhanov, V. 'Chzhan, A.S. Ilyushin, M. Miller, A. Zaleski, K. Nenkov, L. Schultz. IEEE Trans. Magn. 50, 2504604 (2014).

[35] Г.А. Политова, А.Ю. Карпенков, Т.П. Каминская, М.А. Ганин, Рави Кумар, А.В. Филимонов. Научн.-техн. ведомости Санкт-Петербургского гос политехн. ун-та. Физ.-мат. науки, 12, 1, 28 (2019).

[36] G. Politova, M. Ganin, T. Kaminskaya, A. Mikhailova, B. Nacke, A. Filimonov, G. Burkhanov. J. Phys.: Conf. Ser. 389, 012097 (2019).

Редактор Д.В. Жуманов 